\title{
ANTI-TUMOUR EFFECTS OF POLYSACCHARIDES ISOLATED FROM ARTEMISIA ANNUA L BY INDUCING CELL APOPTOSIS AND IMMUNOMODULATORY ANTI-HEPATOMA EFFECTS OF POLYSACCHARIDES
}

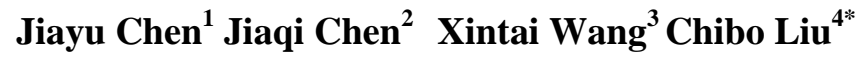

\author{
${ }^{1}$ Medical School of Taizhou University, Taizhou, Zhejiang 318000, China, ${ }^{2}$ College of Life Science, Jilin University, \\ Changchun, Jilin, 136000; ${ }^{3}$ Haiyan People's Hospital, Jiaxing, Zhejiang Province, 314300, China \\ ${ }^{4}$ Departments of Laboratory Medicine, Taizhou Municipal Hospital, Taizhou, Zhjiang 318000, China \\ *E-mail: chibo_liu@163.com
}

\begin{abstract}
Background: It is well known that various polysaccharides present anti-tumour effects by inducing cell apoptosis and immunomodulation. However, it is still unclear about the roles of polysaccharides isolated from Artemisia apiacea (HQG) to hepatoma and its underlying mechanism. The objective of the study was to examine the anti-hepatoma effects of HQG and its related mechanism.

Materials and Methods: HQG was prepared in house and the quality and purity were confirmed by infra-red spectrum and gel permeation chromatography (GPC). Tumour-bearing mice induced by injection of mouse hepatoma H22 cells were used to evaluate the tumour growth inhibition by HQG administration. Cell immunostaining, JC1 staining and flow cytometer were performed to examine the cell apoptosis, mitochondrial membrane potential change and immunomodulation in response to HQG treatment.

Results: HQG treatment inhibited hepatoma growth in tumour-bearing mice. Cell apoptosis rate of human hepatoma 7402 cells and of the cells from ascites in tumour-bearing mice was increased after HQG treatment. Mitochondrial membrane potential in human hepatoma 7402 cells was decreased after HQG treatment. CD4+ and CD8+ T- lymphocytes subpopulation was increased while the ratio of CD4+/ CD8+ decreased in tumour-bearing mice after HQG administration. IFN- $\gamma$ and IL-4 secretion was increased in spleen lymphocytes in tumour-bearing mice after HQG administration.

Conclusion: The study concluded that polysaccharides isolated from Artemisia apiacea (HQG) can inhibit hepatoma cell growths by facilitating cell apoptosis and immuno-defence.
\end{abstract}

Keywords: Polysaccharides isolated from Artemisia apiacea (HQG), anti-tumour effects, tumour growth, cell apoptosis, immunomodulation

\section{Introduction}

Cancer is always one of the leading death causes with high morbidity and mortality in human history. With the advancement of understanding to tumorigenesis, in the past five decades, the conventional medical treatments to cancers including chemotherapy radiotherapy, and surgery significantly improved the survival of patients with malignant cancers. Nevertheless, the overall therapeutic outcomes are still far from satisfactory (Mushiake et al., 2005), since more and more evidences show that the current approaches to cancer therapy have severe side effects, even adverse effects, such as the disruption of the body's natural defence (Andrews et al., 2012; Chabner et al., 2005). Therefore, new strategies to cancer treatment are being developed to combat the disease. Among them, immunotherapeutic is viewed as the most promising approach against cancer (Borghaei et al., 2009).

Recently, plant-derived polysaccharides have been paid more and more attention due to their anti-cancer activities and their capability to improve the body's immunomodulation (Yoon et al., 2003; Nergard et al., 2004; Nam et al., 2009; Du et al., 2012). In oriental medicine, there has been a long history of herbal use to prevent and treat diseases, including cancers, by modulating the body's natural immune-defence system. It was revealed that, among those herbs, polysaccharides are the major active ingredients exerting therapeutic efficacy. For example, polysaccharides extracted from Sparassis crispa (Harada et al., 2002), Platycodon grandiflorum (Yoon et al., 2003), Vernonia kotschyana (Nergard et al., 2004), Asterina pectinifera (Kim,et al., 2012) and more have been demonstrated to possess anti-cancer activities.

Polysaccharides isolated from Artemisia apiacea (HQG) are commonly used active extracts. Initial investigations indicated that HQG may also play significant roles in anti-cancer activities. However, the underlying mechanism is poorly understood. In this study, we firstly isolated HQG and then characterised the polysaccharides in the hepatoma cells and cancer-bearing mice model. Our results indicated that HQG exerts anti-hepatoma activity by inducing cell apoptosis and promoting immunomodulation.

\section{Materials and Methods \\ Preparation, purification and concentration measurement of HQG}

The isolation and purification of crude polysaccharide were described previously (Cao et al., 2010). Briefly, the $4.0 \mathrm{~kg}$ of powdered Artemisia apiacea (Youyang, Chongqing, China) were extracted three times with ethanol at $80^{\circ} \mathrm{C}$ for $3 \mathrm{~h}$. The residues were decocted three times with water at $100^{\circ} \mathrm{C}$ for $3 \mathrm{~h}$. After $3000 \mathrm{x}$ g centrifugation for $10 \mathrm{~min}$, the aqueous extract was concentrated at $60^{\circ} \mathrm{C}$ in vacuum and treated with three volumes of ethanol for precipitation at $4{ }^{\circ} \mathrm{C}$ overnight. The gel-like precipitate was suspended in water and dialysed against distilled water (exclusion limit $3.5 \mathrm{kD}$ ). The non-dialyzable portion was frozen at $-20^{\circ} \mathrm{C}$, then thawed and centrifuged again to remove insoluble materials. After the freeze-thaw process was repeated ten times, the supernatant was lyophilised and the crude polysaccharides fraction was obtained. The crude polysaccharides (4\%) was dissolved in distilled water and loaded onto a DEAE-Sephadex A-25 column $(90 \mathrm{~cm} \times 5 \mathrm{~cm})$. The column was successively eluted with distilled water, $0.3 \mathrm{M}$ and $0.5 \mathrm{M} \mathrm{NaCl}$ each time until the disappearance in elute of positive reaction for carbohydrate by the phenol-sulphuric acid method. The $0.5 \mathrm{M} \mathrm{NaCl}$-eluted fraction was collected, dialysed, lyophilised. The fraction containing carbohydrate was pooled, dialysed, lyophilised, and further applied onto the column of Sephadex G-100 $(100 \mathrm{~cm} \times 3.5 \mathrm{~cm})$ to get purified polysaccharides. The key fraction was concentrated, dialysed and lyophilised. 
http://dx.doi.org/10.4314/ajtcam.v11i1.2

The molecular weights of the polysaccharides were determined by gel permeation chromatography (GPC) using a Waters 515 gel permeation chromatography equipped with a TOSOH BIOSEP TSK-Gel G4000SWXL (7.8x300mm, Japan ) column. The columns were eluted with 0.1M nitric acid and calibrated with standard Dextran (Sigma, St. Louis, MO, USA). The elution was monitored by Waters Alliance 2410 RI detector (Waters, Milford, MA, USA).

The carbohydrate was quantified by the phenol-sulphuric acid method, using d-glucose as the standard. Protein contents were measured by the Bradford method using bovine serum albumin as standard. Each sample was analysed three times by the methods described above.

LPS contamination was tested by Limulus amebocytes lysate (LAL) assay. In brief, $0.1 \mathrm{ml}$ of samples $(5 \mathrm{mg} / \mathrm{mL}$ ), standards or endotoxin-free water was mixed with $0.1 \mathrm{ml}$ of LAL for $1 \mathrm{~h}$ at $37^{\circ} \mathrm{C}$ and observed for gelation.

\section{Cells, cell culture and treatment}

Mouse hepatoma H22 cells and human hepatoma cell line 7402 were got from Institute of Biochemistry and Cell Biology, Chinese Academy of Sciences (Shanghai, China). Cells were maintained in RPMI 1640 medium (Invitrogen, Carlsbad, CA, USA) supplemented with 10\% (v/v) Foetus Bovine Serum (Invitrogen, Carlsbad, CA, USA), 100 unit $/ \mathrm{ml}$ penicillin, 100 unit $/ \mathrm{ml}$ streptomycin in humidified atmosphere with $5 \% \mathrm{CO}_{2}$ at $37^{\circ} \mathrm{C}$. Culture medium was daily replaced with fresh medium when cell confluency reached 80 90\%. To examine the apoptosis effects induced by HQG, 7402 cells were treated with HQG at final concentration of $2 \mu \mathrm{g} / \mathrm{mL}, 10 \mu \mathrm{g} / \mathrm{mL}, 50 \mu \mathrm{g} / \mathrm{mL}$ or $250 \mu \mathrm{g} / \mathrm{mL}$ for $48 \mathrm{~h}$. Afterwards, JC-1 staining and Hochest staining were performed. For JC-1 staining, the stock solution of JC-1 (Invitrogen; Carlsbad, CA, USA) in DMSO (5 mg/ml) was diluted to $2 \mu \mathrm{g} / \mathrm{ml}$ with RPMI 1640 medium. Then cells were incubated in the dilution JC-1 solution for 30 min. Afterwards, cells were rinsed three times with PBS and then were inspected under microscope. For Hochest staining, cells were firstly fixed with methanol/glacial acetic acid (3:1) for $15 \mathrm{~min}$. After washing twice with PBS, cells were incubated in Hochest staining solution (Invitrogen; Carlsbad, CA, USA) for 5 min at $37^{\circ} \mathrm{C}$. After another washing twice with PBS, cells were inspected under microscope.

\section{Mice injection, measurement of tumour weight and cell apoptosis analysis}

Healthy H22 cells were harvested and pre-washed with sterilised PBS three times. One day after inguen hypodermal injection of $100 \mu 1$ of PBS with final cell density of $1 \times 10^{7} / \mathrm{ml}$ to male mice with 5-week age, mice were administered with $0.5 \mathrm{ml}$ of $\mathrm{HQG}$ in ddH $\mathrm{H}_{2} \mathrm{O}$ (the content of HQG was $12.5 \mathrm{mg} / \mathrm{kg}, 25 \mathrm{mg} / \mathrm{kg}, 50 \mathrm{mg} / \mathrm{kg}$ and $100 \mathrm{mg} / \mathrm{kg}$, respectively). Ten days after administration, mice were sacrificed and the induced tumour was weighted. This study was carried out in strict accordance with the recommendations in the Guide for the Care and Use of Laboratory Animals of Taizhou University (Taizhou, China). The protocol was approved by the Committee on the Ethics of Animal Experiments, Taizhou University (approval ID: TZ-SKY-010).

Healthy H22 cells were harvested and pre-washed with sterilised PBS three times. One day after abdomen injection of $500 \mu 1$ of PBS with final cell density of $1 \times 10^{7} / \mathrm{ml}$ to male mice with 5 -week age, mice were administered by gavage with $0.5 \mathrm{ml}$ of $\mathrm{HQG}$ in ddH $\mathrm{H}_{2} \mathrm{O}$ (the amount of $\mathrm{HQG}$ in $\mathrm{ddH}_{2} \mathrm{O}$ was mouse weight-dependent, according to the criteria of $50 \mathrm{mg} / \mathrm{kg}$ ) or only $0.5 \mathrm{ml}$ of $\mathrm{ddH}_{2} \mathrm{O}$ (as control group). Seven days after administration, ascites were extracted and cells were prepared from ascites. After three times of washing with PBS, cell apoptosis was analysed by Annexin V-FITC/PI (Invitrogen, Carlsbad, CA, USA) double staining followed by flow cytometry analysis.

\section{Preparation of mice spleen lymphocytes}

Mice with $\mathrm{HQG}$ or $\mathrm{ddH}_{2} \mathrm{O}$ administered ( $50 \mathrm{mg} / \mathrm{kg}$ of $\mathrm{HQG}$ in $\mathrm{ddH}_{2} \mathrm{O}$ ) as described previously were sacrificed, and then freshly extracted mice spleens were incubated in RPMI 1640 medium supplemented with $10 \%$ FCS. Spleens were milled on 200-nylon net with sterilised handle of syringe followed by centrifugation with $500 \mathrm{x}$ g for $15 \mathrm{~min}$. After the supernate was discarded, spleen lymphocytes were resuspended with $5 \mathrm{ml}$ of pH 7.2 Tris- $\mathrm{NH} 4 \mathrm{Cl}$ and incubated for $10 \mathrm{~min}$. After washing twice with RPMI 1640 medium, cells were maintained in complete RPMI 1640 medium supplemented with $10 \%$ FCS with final cell density of $1 \times 10^{7} / \mathrm{ml}$.

\section{Mice spleen lymphocytes staining and $\mathrm{CD4}^{+} / \mathrm{CD8}^{+}$analysis}

Blood samples from mice eyeball and prepared mice spleen lymphocytes in Eppendorf tube were centrifuged with $500 \mathrm{x} g$ for $15 \mathrm{~min}$. After the removal of supernatant, $500 \mu \mathrm{l}$ of pre-warmed $\left(37^{\circ} \mathrm{C}\right) 4 \%$ paraformaldehyde (Sigma, St. Louis, MO, USA) in PBS was added to each tube to suspend cells for $5 \mathrm{~min}$ at room temperature. $3 \mathrm{ml}$ of ice-cold staining buffer was then added with the incubation for $5 \mathrm{~min}$ at $4{ }^{\circ} \mathrm{C}$ followed by 200 $\mathrm{x} g$ centrifugation for $10 \mathrm{~min}$ to remove supernatant. $1 \mu \mathrm{l}$ of fluorescent-labelled CD4 ${ }^{+}$or $\mathrm{CD}^{+}$antibodies (BD Pharmingen; San Diego, CA, USA) diluted in $50 \mu \mathrm{l}$ of DPBS was added in each tube with incubation for $30 \mathrm{~min}$ in darkness. Afterwards, cells were washed three times with DPBS and suspended in $200 \mu 1$ of PBS for flow cytometry analysis.

\section{Analysis of IL-4 and IFN- $\gamma$ in mice spleen lymphocytes}

$2 \mathrm{ml}$ of prepared mice spleen lymphocytes in Eppendorf tube were centrifuged with $500 \mathrm{xg}$ for $5 \mathrm{~min}$. After the removal of supernatant, cell density was adjusted to $1 \times 10^{6} / \mathrm{ml}$ with RPMI 1640 medium supplemented with $10 \%$ FCS, $20 \mathrm{ng} / \mathrm{mL}$ of phorbol 12-myristate 13 -acetate (PMA) (Sigma, St. Louis, MO, USA), $500 \mu \mathrm{g} / \mathrm{mL}$ ionomycin (Sigma, St. Louis, MO, USA) and $10 \mu \mathrm{mol} / \mathrm{L}$ monensin (Sigma, St. Louis, MO, USA). Cells were then seeded in 24-well plate with $2 \mathrm{ml} /$ well and maintained in humidified atmosphere with $5 \% \mathrm{CO}_{2}$ at $37^{\circ} \mathrm{C}$ for $4 \mathrm{hrs}$. Afterwards, cells were harvested and briefly rinsed once with wash buffer and re-suspended for 15 min at $4^{\circ} \mathrm{C}$ in wash buffer containing $10 \%$ FBS (v/v) by adjusting cell density to $1 \times 10^{6} / \mathrm{ml} .500 \mu \mathrm{l}$ of $37^{\circ} \mathrm{C}$ pre-warmed $4 \%$ paraformaldehyde (Sigma, St. Louis, MO, USA) in PBS was added to each tube to suspend cells for $5 \mathrm{~min}$ at room temperature. $3 \mathrm{ml}$ of ice-cold DPBS was then added with incubation for $5 \mathrm{~min}$ at $4^{\circ} \mathrm{C}$ followed by $200 \mathrm{x} \mathrm{g}$ centrifugation for $10 \mathrm{~min}$ to remove supernatant. Cell pellets were suspended in $100 \mu \mathrm{l}$ of FACS permeable solution for 10 min at room temperature to disrupt membrane. Labelled antibodies against intracellular cytokines IL-4 and IFN- $\gamma$ (BD Pharmingen; San Diego, CA, USA) were added in tubes with incubation for $30 \mathrm{~min}$ in darkness according to the antibody usage in instruction manual. Finally, cells were pelleted and suspended in $200 \mu \mathrm{l}$ of DPBS for flow cytometry analysis. 
http://dx.doi.org/10.4314/ajtcam.v11i1.2

\section{Results}

\section{Preparation of HQG}

The method of HQG preparation was described in Materials and Method. The prepared HQG was examined by infra-red spectrum (Figure 1, A) and gel permeation chromatography (GPC) (Figure 1, B; Table 1). Apparently, the extracted polysaccharides with molecular weight $\sim 7,000$ Da matched well with HQG. The purity of HQG was evaluated by phenol-sulphuric acid method with more than $95 \%$ and LAL analysis showed no LPS contamination in HQG. These results demonstrated that the extracted HQG in house was with high quality and purity. Accordingly, we used the self-prepared HQG for the following experiments.

A.

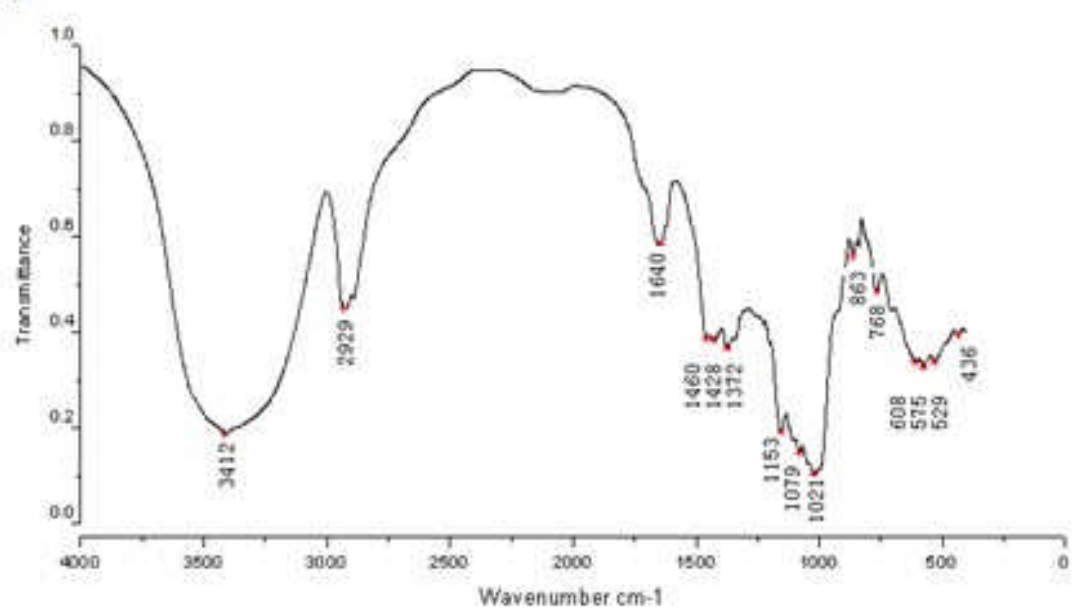

B.

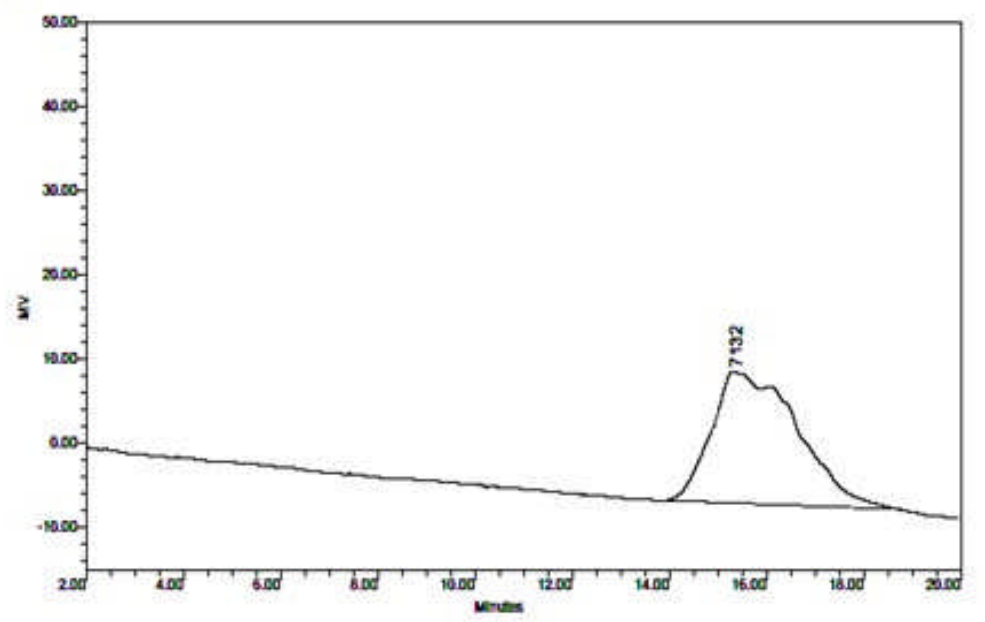

Figure 1: Preparation of HQG: The extracted HQG (See Materials and Methods) were analysed by infra-red spectrum (A) and gel permeation chromatography $(\mathbf{B})$.

Table 1: The parameters of gel permeation chromatography of prepared HQG

\begin{tabular}{ccccccccc}
\hline Retention Time & $\mathrm{Mn}$ & $\mathrm{Mw}$ & $\mathrm{Mp}$ & polydispensity & \%Area & Mz+1 & Mz & Area \\
\hline 15.342 & 3780 & 5525 & 7132 & 1.461780 & 100.00 & 9004 & 7331 & 1958220 \\
\hline
\end{tabular}

\section{HQG treatment inhibits tumour growth}

To investigate the anti-tumour effects of HQG, mice were injected with hepatoma H22 cells followed by administering different dose of HQG by gavage (see Materials and Methods). Tumours induced by $\mathrm{H} 22$ cell injection were then extracted and weighed. In the control mice group without HQG administration, the average weight of induced tumour was $11.3 \pm 0.24 \mathrm{~g}$. When administering with final content of $12.5 \mathrm{mg} / \mathrm{kg} \mathrm{HQG}$, some tumour cells planted into the mice were restrained, only six mice grew solid tumours, and the average weight of induced tumour was significantly reduced to $4.15 \pm 2.06 \mathrm{~g}(P<0.05)$. Apparently, the effects of tumour growth inhibition were with the dose-dependent manner of HQG administration. The number of the mice with tumour was reduced to 4 in other higher dosage HQG groups. And the average weight of the tumour declined from $3.24 \pm 1.51 \mathrm{~g}(P<0.05)$ in response to final content of $25 \mathrm{mg} / \mathrm{kg} \mathrm{HQG}, 2.12 \pm 0.98 \mathrm{~g}(P<0.05)$ in response to final content of $50 \mathrm{mg} / \mathrm{kg}$ HQG till to $2.10 \pm 0.79 \mathrm{~g}(P<0.05)$ in response to final content of $100 \mathrm{mg} / \mathrm{kg}$ HQG (Figure 2; Table 2). According to the effects of tumour growth inhibition, we then used $50 \mathrm{mg} / \mathrm{kg}$ HQG administration for the following experiments. 
http://dx.doi.org/10.4314/ajtcam.v11i1.2

Table 2: Average weight of induced tumour in response to HQG administration

\begin{tabular}{cccccc}
\hline HQG & $0 \mathrm{mg} / \mathrm{kg}$ & $12.5 \mathrm{mg} / \mathrm{kg}$ & $25 \mathrm{mg} / \mathrm{kg}$ & $50 \mathrm{mg} / \mathrm{kg}$ & $100 \mathrm{mg} / \mathrm{kg}$ \\
\hline Average weight $(\mathrm{g})$ & $11.3 \pm 0.24$ & $4.15 \pm 2.06$ & $3.24 \pm 1.51$ & $2.12 \pm 0.98$ & $2.10 \pm 0.79$ \\
\hline
\end{tabular}

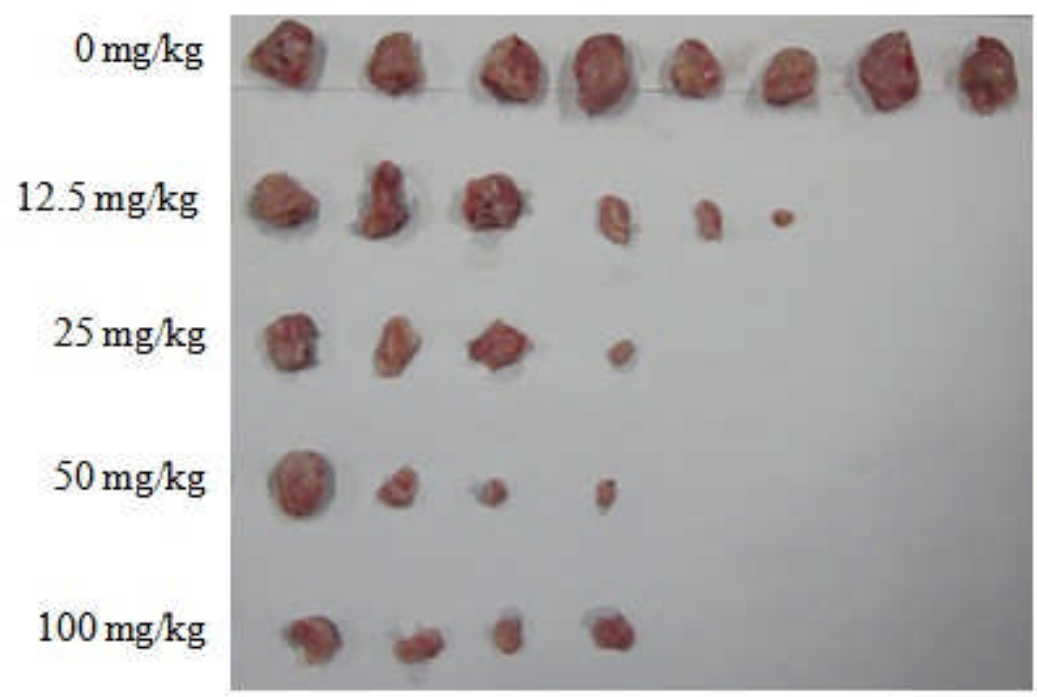

Figure 2: HQG treatment inhibits tumour growth: Tumour-bearing mice were administered with indicated doze of HQG. Ten days after administration, mice were sacrificed and the induced tumours were extracted and pictured. $X$ axle means the number of tumours formed in the mice with tumour cell injection. Y axle means the different doze of HQG administration to tumour-bearing mice.

\section{HQG treatment induces cancer cell apoptosis}

Tumour cell apoptosis is a universal mechanism to inhibit the growth of solid tumour. To demonstrate whether the inhibited tumour growth was due to the cell apoptosis induced by HQG administration, hepatoma H22 cells were injected into mice abdomen and then 0.5 ml of HQG solution (the amount of HQG in solution was mouse weight-dependent, according to the criteria of $50 \mathrm{mg} / \mathrm{kg}$ ) was administered to mice by gavage. Cell apoptosis in induced ascites was analysed by Annexin V-FITC/PI (Invitrogen; Carlsbad, CA, USA) double staining followed by flow cytometry analysis (see Materials and Methods). The results showed that, compared to the control group (2.31 $\pm 0.62 \%)$, HQG administration markedly increased the cell apoptosis rate to $11.42 \pm 1.29(P<0.05)$ (Figure 3, A and B).

To further verify this, cultured human hepatoma 7402 were treated with HQG and then Hoechst 33342 (Invitrogen; Carlsbad, CA, USA) staining was performed to examine the cell morphology. In control group without HQG treatment, cells kept the normal morphology (Figure 3, C), while when HQG treatment introduced, typical apoptotic morphology changes were observed (Figure 3, D). The decrease of mitochondrial membrane potential is a common event in early cell apoptosis stage. To reveal the mechanism by which HQG induced cell apoptosis, with JC-1 staining [11, 12], we next evaluated the changes of mitochondrial membrane potential in 7402 cells without or with HQG treatment. In 7402 cells without HQG treatment, J-aggregates with red fluorescence were clearly observed (Figure 3, E). However, after HQG treatment, more J-monomers with green fluorescence was observed, suggesting mitochondrial membrane potential was decreased in response to HQG treatment. Taken together, these results demonstrated that HQG induced cell apoptosis both in vitro and in vivo.

\section{HQG treatment facilitates immunomodulation in lymphocytes}

To evaluate the immunomodulation by HQG in anti-cancer effects, we firstly examined the CD4 ${ }^{+}$and $\mathrm{CD} 8^{+} \mathrm{T}$-lymphocyte subpopulations in prepared tumour-bearing mice spleen lymphocytes by flow cytometer. Compared with the control tumour-bearing mice group without HQG administration (Figure 4, A), the treatment with HQG to tumour-bearing mice caused a significant increase in the number of CD4 ${ }^{+} \mathrm{T}$ lymphocyte from $9.66 \pm 0.47$ to $21.88 \pm 1.21(P<0.05)$ and an increase in the number of $\mathrm{CD}^{+} \mathrm{T}$ lymphocyte from $6.11 \pm 0.36$ to $10.57 \pm 1.02(P<0.05)($ Figure 4 , B). By calculating the ratio of $\mathrm{CD}^{+} / \mathrm{CD}^{+} \mathrm{T}$ lymphocytes, we also found that the ratio of $\mathrm{CD}^{+} / \mathrm{CD} 8^{+}$in mice administered with $\mathrm{HQG}$ was significantly higher than that in control mice (Table 3), suggesting HQG treatment effectively facilitated the immunoregulation in tumour-bearing mice.

Table 3: The average percentage of CD4+ and CD8+ T lymphocytes subpopulation

\begin{tabular}{ccc}
\hline & Without HQG administration & With HQG administration \\
\hline $\mathrm{CD}^{+}$ & $9.53 \pm 0.47$ & $21.38 \pm 0.51$ \\
$\mathrm{CD}^{+}$ & $6.18 \pm 0.36$ & $10.07 \pm 0.32$ \\
\hline
\end{tabular}


Chen et al., Afr J Tradit Complement Altern Med. (2014) 11(1):15-22

http://dx.doi.org/10.4314/ajtcam.v11i1.2

Table 4: The average percentage of cells with IL-4 or IFN- $\gamma$ secretion

\begin{tabular}{cccc}
\hline & Normal & Without HQG administration & With HQG administration \\
\hline IL-4 ${ }^{+}$cell & $0.03 \pm 0.01$ & $0.04 \pm 0.01$ & $0.17 \pm 0.07$ \\
$\mathrm{IFN}-\gamma^{+}$cell & $0.42 \pm 0.03$ & $0.93 \pm 0.06$ & $1.38 \pm 0.19$ \\
\hline
\end{tabular}

A.

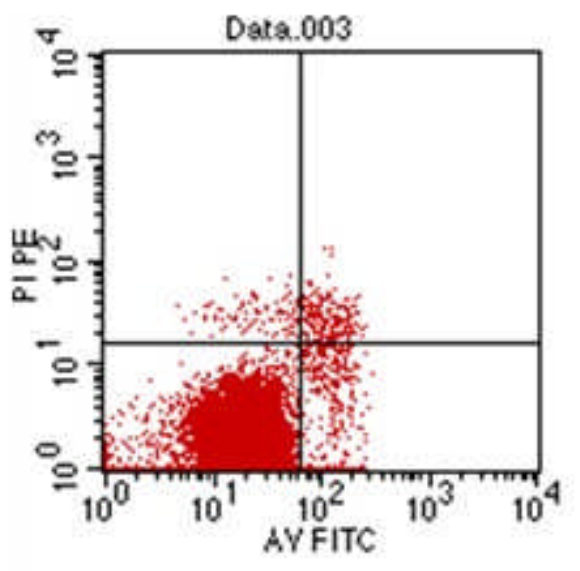

\begin{tabular}{cr} 
Quad & \% Gated \\
\hline UL & 0.69 \\
UR & 1.58 \\
LL & 95.12 \\
LR & 2.61
\end{tabular}

C.

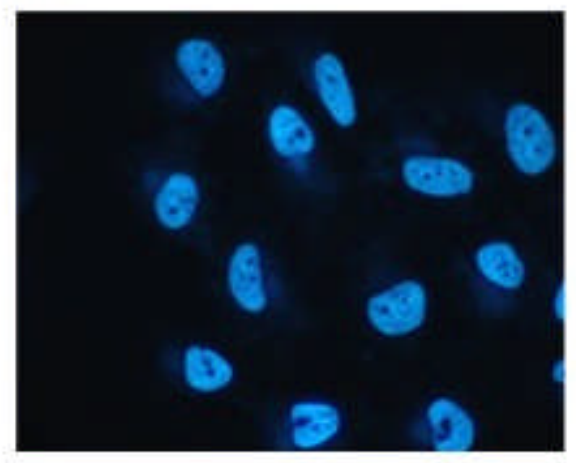

E.

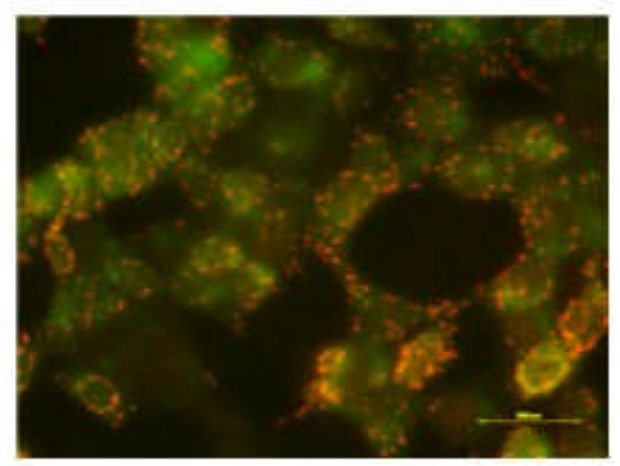

B.

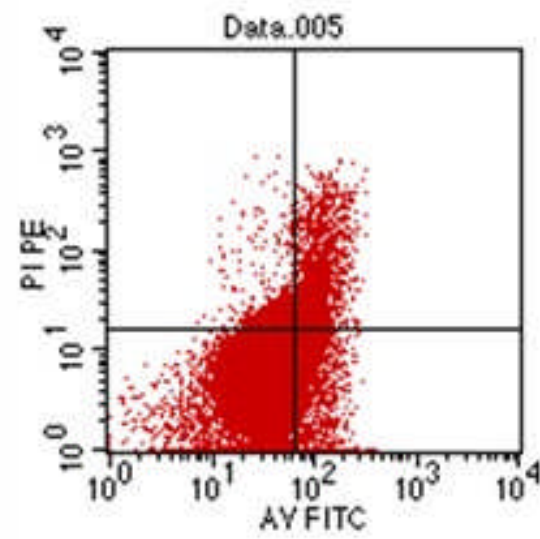

\begin{tabular}{lr} 
Quad & \% Gated \\
\hline UL & 8.43 \\
UR & 8.26 \\
LL & 72.98 \\
LR & 10.33
\end{tabular}

D.

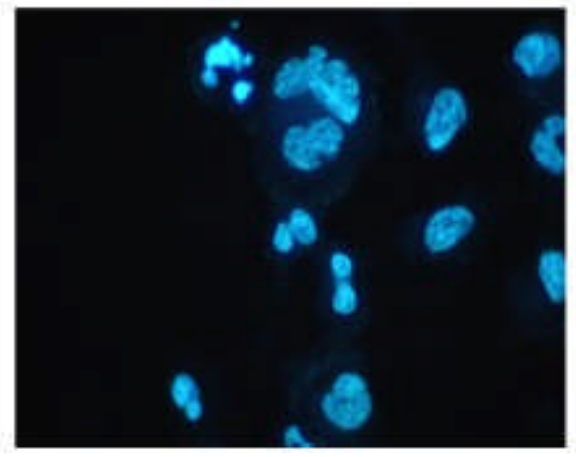

F.

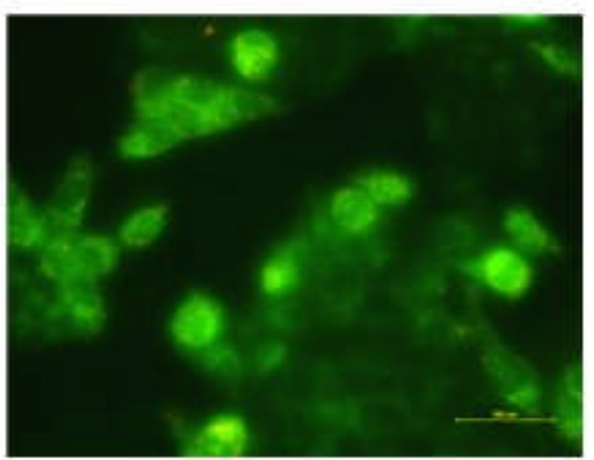

Figure 3: HQG treatment induces cancer cell apoptosis: Cells from the ascites of tumour-bearing mice without (A) or with (B) HQG administration were stained by Annexin V-FITC/PI followed by flow cytometry analysis to analyse cell apoptosis. UL represents the percentage of dead cells; UR represents the percentage of non-active cells; LR represents the percentage of apoptotic cells; LL represents the percentage of living cells. Human hepadoma 7402 cells were treated with $(\mathbf{D}, \mathbf{F})$ or without $(\mathbf{C}, \mathbf{E}) \mathrm{HQG}(50 \mu \mathrm{g} / \mathrm{mL})$ for $48 \mathrm{hrs}$ and then Hoechst 33342 and JC-1 staining was performed to examine the cell morphology. 
A.
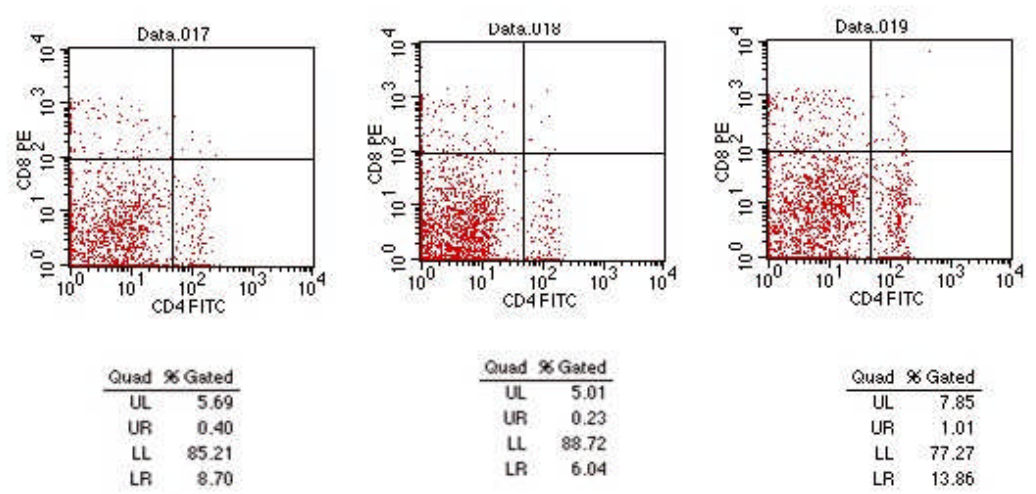

B.
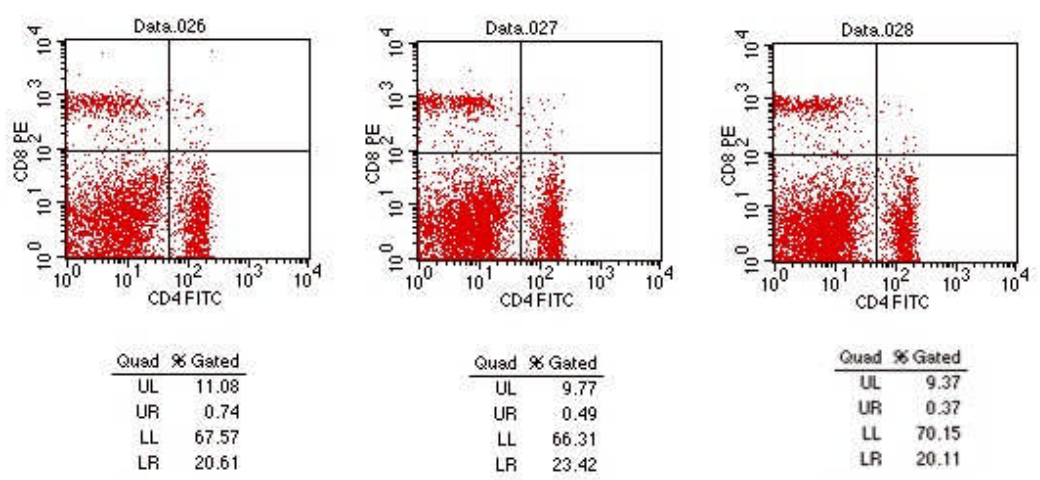

C.

(a)

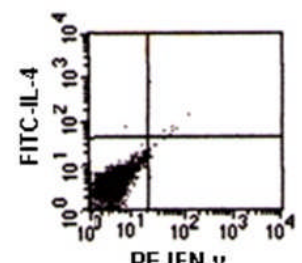

PE-IFN-Y

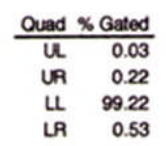

D.

(d)
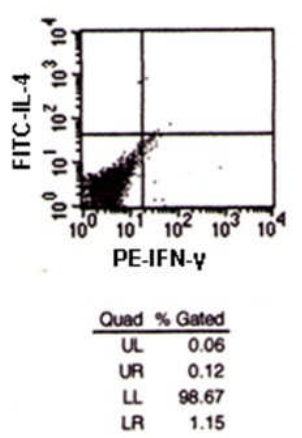

(b)
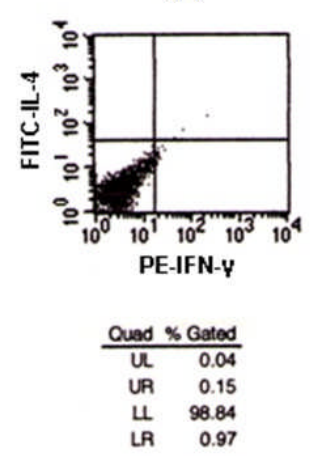

(e)
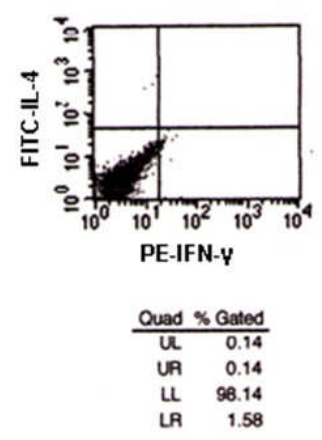

(c)
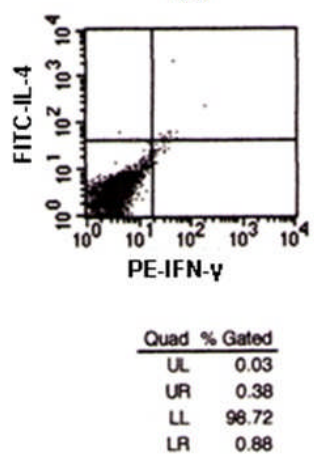

(f)
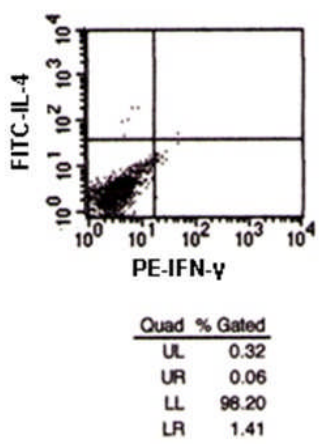

Figure 4: HQG treatment facilitates immunomodulation in lymphocytes: Prepared mice spleen lymphocytes from the tumour-bearing mice with (B) or without (A) HQG administration were fixed, stained with fluorescent-labelled $\mathrm{CD}^{+}{ }^{+}$or $\mathrm{CD}^{+}$antibodies for 30 min followed by flow cytometry analysis to measure the percentage of $\mathrm{CD}^{+}$or $\mathrm{CD}^{+} \mathrm{T}$-lymphocytes subpopulation. See detailed experimental protocol in Materials and Methods. UL means the percent of $\mathrm{CD} 8^{+}$cells, equal to the Th1 cells; LR means the percent of $\mathrm{CD} 4^{+}$cells, equal to the Th2 
http://dx.doi.org/10.4314/ajtcam.v11i1.2

cells; LL means the $\mathrm{CD}^{-} \mathrm{CD} 8^{-}$cells; UR means the $\mathrm{CD} 4^{+} \mathrm{CD} 8^{+}$cells. Prepared mice spleen lymphocytes from normal mice $(\mathbf{C}$, a), tumour-bearing mice without $(\mathbf{C}, \mathbf{b}, \mathbf{c})$ HQG or tumour-bearing mice with HQG administration $(\mathbf{C}, \mathbf{d}, \mathbf{f})$ were fixed, stained and labelled antibodies against intracellular cytokines IL-4 and IFN- $\gamma$ for 30 min followed by flow cytometry analysis to measure the percentage of cells secreting IL-4 (C, upper panel) or IFN- $\gamma$ (C, lower panel). See detailed experimental protocol in Materials and Methods. UL: the percentage of IL- $4^{+}$cells; LR: the percentage of IFN $-\gamma^{+}$cells.

Finally, we assessed the effects of HQG on the secretion of IFN- $\gamma$ and IL-4 in prepared tumour-bearing mice spleen lymphocytes by flow cytometry. As shown in Figure 4C, compared with normal mice (a) and control tumour-bearing mice without HQG administration (b, c), the treatment with HQG to tumour-bearing mice resulted in significantly increased cell percentage with IFN- $\gamma$ and IL-4 secretion (d-f, Table 4). Collectively, these results demonstrated that HQG treatment enhanced the cellular and humoral immunity to defence H22 injection-induced tumorigenesis.

\section{Discussion}

In cancer therapy, besides the conventional chemotherapy, radiotherapy and surgery, immunotherapy with active compounds in natural products represents a promising strategy, since this strategy is with much less negative effects on cancer treatment by improving body's immune-defence system. Among these active compounds, multiple plant-derived and microorganism-isolated polysaccharides have been experimented for anti-cancer and immunostimulating activities (Harada et al., 2002; Yoon et al., 2003; Nergard et al., 2004; Nam et al., 2009; Won et al., 2011).

In this study, we initially isolated polysaccharides from Artemisia apiacea (HQG) and with infra-red spectrum and gel permeation chromatography, we showed that the isolated HQG was with high purity (>95\%). Using hepatoma cells and cancer-bearing mice model, we comprehensively investigated the impact of HQG on cell apoptosis and mice immunomodulation. We revealed that HQG treatment significantly induced cell apoptosis and changed the mitochondrial membrane potential. Furthermore, in cancer-bearing mice, HQG administration markedly reduced the size of solid tumour and decreased the T-lymphocytes subpopulation ratio of $\mathrm{CD}^{+} / \mathrm{CD} 8^{+}$; however, IFN- $\gamma$ and IL- 4 secretion was increased in spleen lymphocytes. Collectively, these results clearly showed that HQG is with anti-hepatoma activity by inducing cell apoptosis and stimulating immunomodulation.

In cellular level, tumorigenesis is the disorder of cell proliferation and cell apoptosis, namely unlimited cell proliferation and excessively low rate of cell apoptosis. In cancer therapy, it is accepted that the inhibition of cancer cell proliferation only delay the progression of tumorigenesis but cannot eliminate tumour, while the induction of cancer cell apoptosis is the effective strategy to reduce the tumour size or even to eliminate tumour (Schulze-Bergkamen et al., 2004). Therefore, the screening of reagents which can induce cancer cell apoptosis is with clinical significance. In this study, after administration with HQG, the induced tumour size in mice was progressively decreased with doze-dependent manner of HQG administration (Figure 2; Table 2). Cell apoptosis analysis showed that after HQG administration, cell apoptosis rate in ascites of cancer-bearing mice was elevated (Figure 3, B and D). Accordingly, this observation well shows that the shrinking of the tumour size is possibly due to the HQG-induced cancer cell apoptosis. Though we did not comprehensively explore the mechanism by which cancer cell apoptosis was induced by HQG, our immuno-staining experiments suggested that HQG treatment decreased mitochondrial membrane potential (Figure 3F), which at least partly contributed to the hepatoma cell apoptosis.

Essentially, tumorigenesis is due to the attenuation of body's immune-defence system, which makes the cancer cells escape attack by the T cells (Weaver, 2012; Foster et al., 2011). Therefore, the stimulation of immunomodulation by reagents will contribute to the elimination of cancer cells in cancer immunotherapy (Han et al., 2006). With HQG administration to tumour-bearing mice, we revealed that not only CD4 ${ }^{+}$and CD8 ${ }^{+}$ T-lymphocytes subpopulation increased (ratio of $\mathrm{CD} 4^{+} / \mathrm{CD}^{+}$increased too), but also the secretion of IFN- $\gamma$ and IL- 4 elevated (Figure 4 ). The results suggested that HQG treatment may bring out two-step effects to mice immunomodulation. Firstly, treatment with HQG to tumour-bearing mice caused a significant increase of $\mathrm{CD}^{+}$and $\mathrm{CD} 8^{+} \mathrm{T}$-lymphocytes subpopulation (Table 3 ). It was documented that $\mathrm{CD} 4^{+} \mathrm{T}$ cells themselves can not only attack cancer cells but also can help $\mathrm{CD}^{+}$T cells to attack cancer cells (Foster et al., 2011; Sun et al., 2012). Thus, the increased $\mathrm{CD}^{+}$and $\mathrm{CD}^{+}$T-lymphocytes subpopulation in response to HQG administration directly enhanced the body's immune-defence system to antagonise tumorigenesis. Secondly, since $\mathrm{CD}^{+} \mathrm{T}$ cells or $\mathrm{CD} 8^{+} \mathrm{T}$ cells secrete multiple cytokines including IFN- $\gamma$ (Mumberg et al.,1999); Vendrell et al., 2011), then upon the increased $\mathrm{CD} 4^{+}$and $\mathrm{CD} 8^{+} \mathrm{T}$ - lymphocytes subpopulation, the amount of secreted IFN- $\gamma$ and IL-4 was further elevated. Given the facts that the production of IFN- $\gamma$ and IL-4 stimulates the Th1-mediated immune-response and Th2-mediated immune-response respectively, then the increased cell percentage with IFN- $\gamma$ and IL-4 secretion suggests the differential immunostimulation pathway in response to HQG treatment. Altogether, the anti-cancer activity of HQG is possibly from the combinative effects of different immunomodulatory pathways activated by HQG.

In conclusion, here we demonstrated that HQG exerts anti-hepatoma activity by inducing cancer cell apoptosis and improving the body's immunomodulation. Our results therefore suggest that HQG is with potential clinical significance in hepatoma therapeutics.

\section{Conflicts of interest}

None

\section{Acknowledgements}

This study was supported by the grants from Zhejiang Natural Science Foundation (Y2100248), Foundation of Department of Science and Technology of Zhejiang Province (2009C33155), Foundation of Zhejiang Health Department (2009A218), Taizhou Science and Technology Bureau (102KY15) and Zhejiang Province Chinese medicine study foundation (2011ZA113).

\section{References}

1. Andrews S, Holden R. (2012). Characteristics and management of immunerelated adverse effects associated with ipilimumab, a new immunotherapy for metastatic melanoma. Cancer Manag Res, 4:299-307.

2. Borghaei H, Smith M.R., Campbell K.S. (2009). Immunotherapy of cancer. Eur J Pharmacol, 625(1-3),41-54. 
http://dx.doi.org/10.4314/ajtcam.v11i1.2

3. Cao W, Li X.Q., Wang X, Li T, Chen X, Liu S.B, Mei Q.B.(2010) Characterizations and anti-tumor activities of three acidic polysaccharides from Angelica sinensis (Oliv.) Diels. International Journal of Biological Macromolecules, 46(1):115-122.

4. Chabner BA, Roberts TG Jr. (2005). Timeline: Chemotherapy and the war on cancer. Nat Rev Cancer,5(1):65-72.

5. Du X, Zhao B, Li J, Cao X, Diao M, Feng H, Chen X, Chen Z, Zeng X.(2012).A Astragalus polysaccharides enhance immune responses of HBV DNA vaccination via promoting the dendritic cell maturation and suppressing Treg frequency in mice. Int Immunopharmacol,14(4):463-70.

6. Foster A.D., Sivarapatna A, Gress R.E. (2011).The aging immune system and its relationship with cancer.Aging health, 7(5):707-718.

7. Harada T, Miura N.N., Adachi Y, Nakajima M, Yadomae T, Ohno N. (2002). IFN-gamma induction by SCG, 1,3-beta-D-glucan from Sparassis crispa, in DBA/2 mice in vitro. J Interf Cytok Res, 22(12):1227-1239.

8. $\quad$ Kim H.S., Choo Y.S., Koo T, Bang S, Oh T.Y., Wen J, Song S.Y. (2006). Enhancement of antitumor immunity of dendritic cells pulsed with heat-treated tumor lysate in murine pancreatic cancer. Immunol Lett, 103(2): 142-148.

9. Mumberg D, Monach PA, Wanderling S, Philip M, Toledano AY, Schreiber RD, Schreiber H.(1999). CD4+T cells eliminate MHC class II-negative cancer cells in vivo by indirect effects of IFN-g gamma. Immunology, 96(15):8633-8638.

10. Mushiake, H, Tsunoda, T, Nukatsuka,M, Shimao K, Fukushima M, Tahara H. (2005). Dendritic cells might be one of key factors for eliciting antitumor effect by chemoimmunotherapy in vivo. Cancer Immunol Immun, 54(2):120-128.

11. Nergard C.S., Diallo D, Michaelsen T.E., Malterud K.E., Kiyohara H, Matsumoto T, Yamada H, Paulsen B.S. (2004). Isolation, partial characterisation and immunomodulating activities of polysaccharides from Vernonia kotschyana Sch. Bip. ex Walp. J Ethnopharmacol 91(1):141-152.

12. Nam K.S., Shon Y.H. (2009). Chemopreventive effects of polysaccharides extract from Asterina pectinifera on HT-29 human colon adenocarcinoma cells. BMB reports, 42(5): 277-280.

13. Schulze-Bergkamen H., Krammer P.H. (2004). Apoptosis in cancer-implications for therapy. Semin oncol, 31(1):90-119.

14. Sun L.X., Lin Z.B., Duan X.S., Lu J, Ge Z.H., Li X.F., Li X.J., Li M, Xing E.H., Song Y.X., Jia J, Li W.D. (2012). Enhanced MHC class I and costimulatory molecules on B16F10 cells by Ganoderma lucidum polysaccharides. J Drug Target,20(7):582-92.

15. Vendrell A, Gravisaco MJ, Pasetti MF, Croci M, Colombo L, Rodríguez C, Mongini C, Waldner CI. (2011). A novel Salmonella Typhi-based immunotherapy promotes tumor killing via an antitumor Th1-type cellular immune response and neutrophil activation in a mouse model of breast cancer. Vaccine, 29(4):728-36.

16. Weaver J.L. (2012). Establishing the carcinogenic risk of immunomodulatory drugs. Toxicol Pathol,40(2):267-71.

17. Won D.P., Lee J.S., Kwon D.S., Lee K.E., Shin W.C., Hong E.K. (2011). Immunostimulating activity by polysaccharides isolated from fruiting body of Inonotus obliquus. Mol Cells,31(2):165-173.

18. Yoon Y.D., Han S.B., Kang J.S., Lee C.W., Park S.K., Lee H.S., Kang J.S., Kim H.M. (2003). Toll-like receptor 4-dependent activation of macrophages by polysaccharide isolated from the radix of Platycodon grandiflorum. Int Immunopharmacol, 3(13-14):1873-1882. 